Special Issue

\title{
Anti-Diabetic Effects of Different Phenolic-Rich Fractions from Rhus Chinensis Mill. Fruits in vitro
}

\author{
Xiaojing Liu, Yishan Fu, Qian Ma, Junjie Yi, Shengbao Cai* \\ Faculty of Agriculture and Food, Yunnan Institute of Food Safety, Kunming University of Science and Technology, Kunming, Yunnan Province 650500, \\ People's Republic of China
}

\section{ARTICLE INFO}

Article History

Received 30 January 2021

Accepted 22 February 2021

Keywords

AGEs inhibition

Chinese sumac

DPP-IV inhibition

$\alpha$-glucosidase inhibition

interaction

\begin{abstract}
This study investigated the inhibitory effects of the Ethanol Extract (EE), Free Phenolic (TF), Esterified Phenolic (TE) and Insoluble-bound Phenolic (TI) from Rhus chinensis Mill. fruits on $\alpha$-glucosidase, Dipeptidyl Peptidase-4 (DPP-IV), and the formation of Advanced Glycation End (AGE) products. Results showed that the TF had the strongest inhibition against $\alpha$-glucosidase and DPP-IV with $\mathrm{IC}_{50}$ of $0.56 \pm 0.04$ and $66.08 \pm 1.36 \mu \mathrm{g} / \mathrm{mL}$, respectively $(p<0.05)$. TI exhibited the strongest inhibitory effect on the formation of AGEs with $\mathrm{IC}_{50}$ of $0.43 \pm 0.03 \mathrm{mg} / \mathrm{mL}(p<0.05)$. Two major compounds (myricetin-3-Orhamnoside and quercetin-3-O-rhamnoside) showed additive or synergistic effects on $\alpha$-glucosidase inhibition, while displayed antagonistic effect on DPP-IV inhibition. Correlation analysis indicated that myricetin-3-O-(6"-galloyl) glycoside and myricetin $O$-gallate contributed significantly on $\alpha$-glucosidase inhibition, while di- $O$-galloyl-glucoside and its isomer may contribute remarkably toward DPP-IV inhibition. Protocatechuic acid and myricetin-3-O-rhamnoside showed a positive correlation with the suppression of AGEs formation. Those results may provide some scientific information for exploring $R$. chinensis fruits as nutraceuticals and/or functional foods to prevent or improve diabetes.
\end{abstract}

\section{GRAPHICAL ABSTRACT}

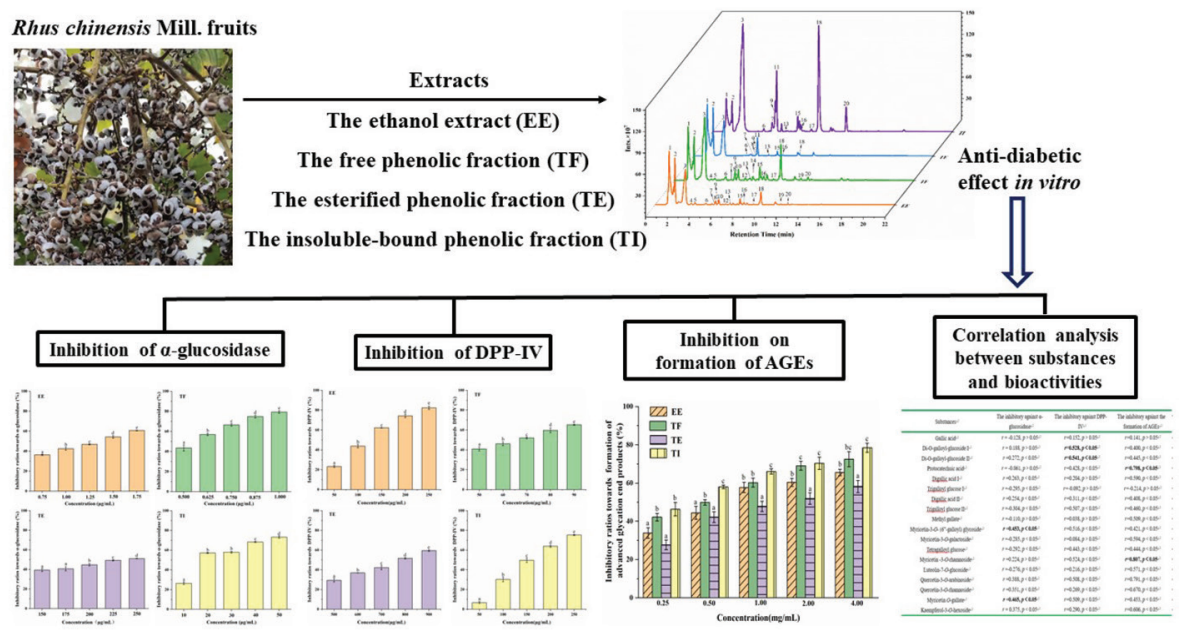

(c) 2021 The Authors. Publishing services by Atlantis Press International B.V. This is an open access article distributed under the CC BY-NC 4.0 license (http://creativecommons.org/licenses/by-nc/4.0/).

\section{INTRODUCTION}

In modern life, people live with a fast-paced lifestyle, intaking with high-fat and high-carbohydrate diets and ignoring the physical exercise, which may lead to many chronic diseases. Diabetes, which could be divided into Type 1 Diabetes Mellitus (T1DM) and Type 2 Diabetes Mellitus (T2DM), is one of the most common chronic

"Corresponding author. Email: caikmust2013@163.com

Peer review under responsibility of the International Association of Dietetic Nutrition and Safety diseases and the prevalence of diabetes has rapidly risen in numbers of countries during the last 30 years, gradually become a global problem [1]. There were 451 million diabetic patients worldwide in 2017 , more than $90 \%$ of them are T2DM patients, and it is estimated that the number of people with diabetes worldwide will reach 600 million by 2040 [2]. The complications, such as diabetic nephropathy, diabetic retinopathy, diabetic neuropathy and the increasing risk of heart disease are more frightening than diabetes itself [3], which seriously affects people's lifespan and quality. Diabetes has not only brought great health effects to patients but also great economic burden on society [4], so how to prevent or 
treat diabetes is a high-profile research topic. The present medical clinical treatments of T2DM mainly possess non-negligible side effects, especially on gastrointestinal tract. Therefore, the exploitation of natural functional foods with minimal or no side effects is urgent. In recent years, there have been kinds of reports to explore the T2DM mechanisms and many studies have confirmed that many plant bioactive ingredients showed good inhibitory activities toward diabetic related enzymes, like $\alpha$-glucosidase, and Dipeptidyl Peptidase-4 (DPP-IV).

In human beings, $\alpha$-glucosidase catalyzes hydrolysis of starch into simple sugars, helping digestion of dietary carbohydrates to produce glucose for intestinal absorption and increase in blood glucose levels. DPP-IV, using Glucose-dependent Insulinotropic Polypeptide (GIP) and Glucagon-like Peptide-1 (GLP-1) as substrates, is another key strategy for blood glucose control. Both GIP and GLP-1 could stimulate insulin biosynthesis, and induce $\beta$-cell differentiation, and thereby, inhibiting DPP-IV could protect GLP-1 and GIP to effectively control blood glucose level $[5,6]$. Diabetic patients are exposed to high levels of glucose for a long time, and this persistent hyperglycemia could induce kinds of aberrant physiological changes. The increasing formation of Advanced Glycation End (AGE) is one of the abnormal physiological changes, which was recognized as the major pathogenesis link between hyperglycemia and complications of diabetes [7]. AGEs are also the causative factor for the pathogenesis of cataracts, atherosclerosis, and neurodegenerative diseases [8]. So, inhibiting the formation of AGEs is an efficient therapy to alleviate diabetic complications to improve the health condition of diabetics.

Rhus chinensis Mill., also known as Chinese sumac, is commonly used as a herb to treat inflammation, diarrhea, malaria, jaundice, alcoholic toxicity and phlegm according to the record of Traditional Chinese Medicine [9]. Previous studies had confirmed that R. chinensis fruits possessed several bioactivities, such as antioxidant and pancreatic lipase inhibitory effects in vitro [10], prevention of liver fibrosis [11], nonalcoholic fatty liver [12] and alcoholic fatty liver [13] in vivo. However, no study has been performed to investigate the in vitro anti-diabetic effect of $R$. chinensis fruits. Therefore, in this study, the effects of different extracts from $R$. chinensis fruits on $\alpha$-glucosidase, DPP-IV and AGEs formation were comparatively investigated, which may be useful for further exploring this kind of fruits as a functional food in preventing or improving diabetes.

\section{MATERIALS AND METHODS}

\subsection{Chemicals and Reagents}

$\alpha$-Glucosidase (from Saccharomyces cerevisiae, EC:3.2.1.20; Type I, lyophilized powder, $\geq 10$ units/mg protein), p-nitrophenyl$\alpha$-D-glucopyranoside (purity $\geq 99.0 \%$ ) were purchased from Sigma-Aldrich (St. Louis, MO, USA). DPP-IV inhibitor screening assay kit was obtained from Cayman Chemicals (Ann Arbor, MI, USA). Bovine Serum Albumin (BSA) was purchased from Beijing BioDee Biotechnology Co., Ltd. (Beijing, China). D-Fructose (purity $299.0 \%$ ) was purchased from Sangon Biotech Co., Ltd. (Shanghai, China). Glutathione (reduced, GSH) and aminoguanidine hydrochloride were obtained from Aladdin Chemistry Co., Ltd. (Shanghai, China). All phenolic standards ( $\geq 98 \%)$ were obtained from Chengdu Must Bio-Technology Co., Ltd. (Chengdu, China). And all other reagents were of the highest available purity.

\subsection{Sample Preparation and Analysis}

Rhus chinensis fruits were collected from Tengchong County, Baoshan City, Yunnan province, China, in November 2019. After sifting the raw materials to remove the branches and leaves, the fruits were washed, freeze-dried, powdered to pass through a 40 -mesh sieve. Then the powder was stored at $-20^{\circ} \mathrm{C}$ for future experiments. The Ethanol Extract (EE), Free Phenolic (TF), Esterified Phenolic (TE) and Insoluble-bound Phenolic (TI) fractions of R. chinensis fruits were prepared according to previous reports $[10,14,15]$. Briefly, as for EE, the defatted fruits were ultrasonically extracted by $80 \%$ ethanol and the solid-liquid ratio was 1:10. The fruits were extracted twice and then filtered and concentrated. After freeze-drying, EE fraction was obtained. The extract methods of other three fractions were as follows: firstly, defatted fruits powder was ultrasonically extracted by the mixture of $70 \%$ methanol and $70 \%$ acetone $(1: 1, \mathrm{v} / \mathrm{v} ; 1: 5, \mathrm{w} / \mathrm{v})$ for $30 \mathrm{~min}$ and then centrifugated. This process was repeated twice and combined filtrate was evaporated (Hei-VAP, Heidolph, Germany) to get the aqueous phase for the further extraction of the soluble phenolic fraction (TF and TE). And the residue was used to extract the TI fraction. The aforementioned aqueous phase was adjusted to $\mathrm{pH} 2$ and then extracted with diethyl ether and ethyl acetate $(1: 1, \mathrm{v} / \mathrm{v})$. Then, the mixture of diethyl ether and ethyl acetate was evaporated and lyophilized to get TF fraction. The remaining aqueous phase was added $4 \mathrm{M}$ of $\mathrm{NaOH}(1: 10, \mathrm{v} / \mathrm{v})$ to be hydrolyzed for $4 \mathrm{~h}$ at room temperature and then the same method performed as TF fraction was used for obtaining TE fraction. As for TI, the remained residues were hydrolyzed with $4 \mathrm{M}$ $\mathrm{NaOH}(1: 10, v / \mathrm{v})$ for $4 \mathrm{~h}$ and filtered and adjusted to $\mathrm{pH} 2$. After that, the same method performed as TF fraction was applied to get TI fraction.

\subsection{Measurement of Total Phenolic and Total Flavonoid Content}

The Total Phenolic Content (TPC) and the Total Flavonoid Content (TFC) of each fraction of $R$. chinensis fruits was measured based on the Folin-Ciocalteu and colorimetric methods, respectively, described earlier [16]. Absorbance of each reaction mixture was measured by a SpectraMax M5 microplate reader (Molecular Device, Sunnyvale, CA, USA).

\subsection{Inhibition of $\alpha$-Glucosidase Assay}

Inhibitory effects of different samples (EE, TF, TE, TI) and acarbose (positive control) toward $\alpha$-glucosidase were measured according to the published study [17]. Absorbances were recorded by a SpectraMax M5 microplate reader. The inhibitory ability of each sample was calculated by the following formula: Inhibitory ratio (\%) = $(1-$ slope of sample/slope of control $) \times 100 \%$.

\subsection{Inhibition of DPP-IV}

Inhibitory effects of four samples and sitagliptin (positive control) against DPP-IV was measured according to the instruction book of the screening assay kit. Inhibition ratio $(\%)=[($ DPP-IV activity of control - DPP-IV activity of sample)/DPP-IV activity 
of control] $\times 100 \%$, where the DPP-IV activity was calculated by using the slope ( $\Delta$ fluorescence/min).

\subsection{Interactions of Myricetin-3-O- rhamnoside and Quercetin-3-O- rhamnoside on $\alpha$-Glucosidase and DPP-IV Inhibition}

Interactions of myricetin-3-O-rhamnoside and quercetin-3-Orhamnoside on $\alpha$-glucosidase and DPP-IV inhibition were analyzed by CalcuSyn software (Biosoft, Ferguson, MO, USA). The dose ratios between myricetin-3-O-rhamnoside and quercetin-3-Orhamnoside were chose as 1:1 and 1:2 according to their content ratio in all extracts in the present work. The interaction effects were determined by Combination Index (CI). CI $\leq 0.90,0.90<\mathrm{CI}<1.10$ and $\mathrm{CI} \geq 1.10$ indicate synergistic, additive and antagonistic effects, respectively.

\subsection{Inhibition of AGEs}

Bovine serum albumin/fructose model was used to evaluate the antiglycation ability of samples according to the previous method [18] with little modification. The total reaction system was made up of $50 \mathrm{mg} / \mathrm{mL}$ BSA, $250 \mathrm{mM}$ fructose and $0.02 \%$ sodium azide with or without inhibitors dissolved in phosphate buffer $(0.2 \mathrm{M}, \mathrm{pH}$ 7.4). BSA alone or fructose alone were set as blank solutions. All mixtures were incubated at $37^{\circ} \mathrm{C}$ for 14 days in the aseptic conditions without light. After incubation, the fluorescence of each mixture was measured by using a Spectra Max M5 microplate reader as $F_{\text {sample }}$. The mixture without inhibitor was defined as blank and the fluorescence was named $F_{\text {control }}$.

$$
\text { Inhibition ratio }(\%)=\left(1-\frac{F_{\text {sample }}}{F_{\text {control }}}\right) \times 100 \% \text {. }
$$

\subsection{Statistical Analysis}

All data in the present work are expressed as the mean value $(n=3) \pm$ Standard Deviation (SD) and analyzed by using one-way analysis of variance. Turkey's procedure was applied for detecting the significance of difference $(p<0.05)$. Pearson's correlation analyses between various phenolic substances and each bioactivity was analyzed by SPSS 21.0 (SPSS Inc., Chicago, IL, USA) and the calculation was based on the content of each compound and inhibitory ratio at certain tested concentration. All other analyses were performed with Origin 8.5 software (OriginLab, Northampton, MA, USA).

\section{RESULTS AND DISCUSSION}

\subsection{TPCs, TFCs and Phytochemical Composition of Different Fractions from R. chinensis Fruits}

The TPCs and TFCs of all fractions are summarized in Table 1. Among those four different fractions, TF fraction possessed the highest TPC with $434.14 \pm 21.31 \mathrm{mg}$ of gallic acid equivalents/g extracts, followed by the EE with TPC of $361.33 \pm 19.90 \mathrm{mg}$ of gallic acid equivalents/g extracts. As for the TFCs, the content of TI was the most with $220.9 \pm 15.57 \mathrm{mg}$ of rutin equivalents/g of extracts, followed by TF, with the content of $162.59 \pm 11.22 \mathrm{mg}$ of rutin equivalents/g of extracts. Previous studies had confirmed that different plants had different phenolic composition, for example, in Lonicera species, free phenolics were the major form [19]. However, the insoluble-bound phenolic fraction was the main phenolic fraction of oil palm fruits [15] and the content of the esterified phenolics were the highest in camelina and sophia seeds [20]. The different results of TPCs or TFCs between the previous reports $[10,14]$ and the current study may due to the different picking years, region and/or growth environment. Previous studies had proved that Acer truncatum leaves at different seasons possessed different phenolic compounds [21]. A studied had also confirmed that the environmental factors contributed more than genetic background on the composition of phenolic acid in rice grains [22].

Phytochemical composition of each fraction from $R$. chinensis fruits was identified by UHPLC-ESI-HRMS/MS in negative mode as shown in Supplementary Figure S1. The phenolic quantification results are presented in Table 1 . Acidified water $(0.1 \%$ formic acid) and acetonitrile were used as the mobile phases $\mathrm{A}$ and $\mathrm{B}$, respectively. The elution gradient as follows: $0-2 \mathrm{~min}, 5 \%-20 \% \mathrm{~B} ; 2-14 \mathrm{~min}$, 20\%-23\% B; 14-17 min, 23\%-5\% B; 17-22 min, 5\% B and the mass spectrometry conditions was as the same as the previous study [10]. A total of 20 phytochemicals were identified in the present work, 18 of which were characterized as phenolic compounds. Among those phenolic compounds, gallic acid and quercetin-3-O-rhamnoside were the most two phenolic compounds that can be detected in all four fractions. This finding was consistent with the results reported earlier $[10,14]$.

\subsection{Inhibition of $\alpha$-Glucosidase and DPP-IV}

Previous studies have already reported that the different extracts of sumac fruits possessed good inhibitory activities toward digestive enzymes. For example, extracts from $R$. chinensis fruits showed excellent inhibitory activities to pancreatic lipase $[10,14]$ and extract from Rhus coriaria L had a good inhibitory activity to $\alpha$-amylase [23]. However, the inhibitory activities of $R$. chinensis fruits on $\alpha$-glucosidase and DPP-IV are still not reported.

The results of inhibitory capacities of different fractions from $R$. chinensis fruits to $\alpha$-glucosidase are illustrated in Figure 1. All samples exhibited good inhibitory abilities toward $\alpha$-glucosidase under the tested concentrations in a dose-dependent manner. Among those extractions, TF possessed the strongest inhibitory ability and $\mathrm{IC}_{50}$ value was $0.56 \pm 0.04 \mu \mathrm{g} / \mathrm{mL}(p<0.05)$, followed by EE with $\mathrm{IC}_{50}$ value of $1.36 \pm 0.04 \mu \mathrm{g} / \mathrm{mL}$ and the $\mathrm{IC}_{50}$ values of the $\mathrm{TI}$ and TE fractions were $27.65 \pm 1.38$ and $230.36 \pm 5.39 \mu \mathrm{g} / \mathrm{mL}$, respectively. Numerous of literatures indicated that the inhibitory activity of $\alpha$-glucosidase is related to phenolic substances in plants. For example, Zhang et al. [24] had found that the major contributors from Lens culinaris to the inhibitory activity on $\alpha$-glucosidase was the phenolic compounds. Moreover, it is found that the enzyme inhibitory capacity of plant extract has close relationship to the phenolic composition [25]. According to the results presented in Table 1 in the present work, these four extracts possessed different composition and contents of phenolic substances, which may explain their different inhibitory capacities. In addition, the 
Table 1 Phytochemical identification and phenolic quantitation of different extracts from Rhus chinensis Mill. fruits by UHPLC-ESI-HRMS/MS

\begin{tabular}{|c|c|c|c|c|c|c|c|c|}
\hline \multirow{2}{*}{$\begin{array}{l}\text { Peak } \\
\text { no. }\end{array}$} & \multirow{2}{*}{ Compounds } & \multirow{2}{*}{$\begin{array}{l}{[\mathbf{M}-\mathbf{H}]^{-}} \\
\quad(m / z)\end{array}$} & \multirow{2}{*}{$\begin{array}{l}\text { Molecular } \\
\text { formula }\end{array}$} & \multirow{2}{*}{ MS2/MS fragment ions } & \multicolumn{4}{|c|}{ Extracts ${ }^{\#, * *}$} \\
\hline & & & & & $\mathrm{EE}$ & TF & TE & TI \\
\hline 1 & Malic acid & 133.0131 & $\mathrm{C}_{4} \mathrm{H}_{6} \mathrm{O}_{5}$ & $115.0024(100)$ & $\sqrt{ }$ & $\sqrt{ }$ & $\sqrt{ }$ & $\sqrt{ }$ \\
\hline 2 & Citric acid & 191.0187 & $\mathrm{C}_{6}^{4} \mathrm{H}_{8}^{6} \mathrm{O}_{7}^{5}$ & $\begin{array}{c}87.0074(100), \\
111.0075(62.20), \\
57.0332(40.32)\end{array}$ & $\sqrt{ }$ & $\sqrt{ }$ & $\sqrt{ }$ & $\sqrt{ }$ \\
\hline 3 & Gallic acid & 169.0134 & $\mathrm{C}_{7} \mathrm{H}_{6} \mathrm{O}_{5}$ & $\begin{array}{c}69.0332(100), \\
125.0232(71.18), \\
124.0154(58.91)\end{array}$ & $32.76 \pm 0.26^{a}$ & $65.37 \pm 2.19^{c}$ & $37.06 \pm 0.27^{\mathrm{b}}$ & $113.20 \pm 0.87^{\mathrm{d}}$ \\
\hline 4 & Di-O-galloyl-glucoside I & 483.0779 & $\mathrm{C}_{20} \mathrm{H}_{20} \mathrm{O}_{14}$ & $\begin{array}{l}169.0134(100) \\
331.0674(14.67)\end{array}$ & $0.80 \pm 0.09^{\mathrm{a}}$ & $0.72 \pm 0.06^{\mathrm{a}}$ & - & - \\
\hline 5 & Di-O-galloyl-glucoside II & 483.0777 & $\mathrm{C}_{20} \mathrm{H}_{20} \mathrm{O}_{14}$ & $\begin{array}{l}169.0134(100) \\
331.0674(13.30)\end{array}$ & $1.25 \pm 0.10^{\mathrm{a}}$ & $1.34 \pm 0.09^{\mathrm{b}}$ & - & - \\
\hline 6 & Protocatechuic acid & 153.0186 & $\mathrm{C}_{7} \mathrm{H}_{6} \mathrm{O}_{4}$ & $\begin{array}{c}108.0204(100) \\
109.0282(73.02) \\
91.0176(20.37)\end{array}$ & $1.36 \pm 0.10^{\mathrm{b}}$ & $3.49 \pm 0.13^{\mathrm{d}}$ & $0.75 \pm 0.05^{\mathrm{a}}$ & $2.95 \pm 0.13^{c}$ \\
\hline 7 & Digallic acid I & 321.0256 & $\mathrm{C}_{14} \mathrm{H}_{9} \mathrm{O}_{9}$ & $\begin{array}{l}125.0233(100) \\
169.0135(78.07)\end{array}$ & $0.18 \pm 0.01^{\mathrm{a}}$ & $0.61 \pm 0.05^{c}$ & $0.31 \pm 0.02^{\mathrm{b}}$ & $4.85 \pm 0.22^{\mathrm{d}}$ \\
\hline 8 & Trigalloyl glucose I & 635.0900 & $\mathrm{C}_{27} \mathrm{H}_{24} \mathrm{O}_{18}$ & $\begin{array}{l}169.0134(100) \\
635.0901(79.50) \\
483.0786(79.02)\end{array}$ & $2.32 \pm 0.18^{b}$ & $5.12 \pm 0.39^{c}$ & $0.28 \pm 0.02^{\mathrm{a}}$ & - \\
\hline 9 & Digallic acid II & 321.0255 & $\mathrm{C}_{14} \mathrm{H}_{10} \mathrm{O}_{9}$ & $\begin{array}{l}125.0233(100) \\
169.0135(78.07)\end{array}$ & $0.69 \pm 0.06^{\mathrm{a}}$ & $1.76 \pm 0.12^{c}$ & $1.03 \pm 0.08^{\mathrm{b}}$ & $15.04 \pm 0.57^{\mathrm{d}}$ \\
\hline 10 & Trigalloyl glucose II & 635.0887 & $\mathrm{C}_{27} \mathrm{H}_{24} \mathrm{O}_{18}$ & $\begin{array}{l}635.0900(100), \\
169.0134(73.41), \\
483.0786(54.12)\end{array}$ & $2.64 \pm 0.16^{\mathrm{a}}$ & $5.52 \pm 0.30^{\mathrm{b}}$ & - & - \\
\hline 11 & Methyl gallate & 183.0293 & $\mathrm{C}_{8} \mathrm{H}_{8} \mathrm{O}_{5}$ & $\begin{array}{l}140.0106(100) \\
139.0027(61.74) \\
124.0155(13.50)\end{array}$ & - & - & $9.55 \pm 0.14^{\mathrm{a}}$ & $31.92 \pm 1.22^{\mathrm{b}}$ \\
\hline 12 & $\begin{array}{l}\text { Myricetin-3-O- } \\
\quad\left(6^{\prime \prime} \text {-galloyl) glycoside }\right.\end{array}$ & 631.0950 & $\mathrm{C}_{28} \mathrm{H}_{23} \mathrm{O}_{17}$ & $\begin{array}{l}479.08369(100) \\
631.0956(86.56)\end{array}$ & $0.51 \pm 0.04^{\mathrm{a}}$ & $1.17 \pm 0.08^{\mathrm{b}}$ & - & - \\
\hline 13 & $\begin{array}{l}\text { Myricetin-3-O- } \\
\text { galactoside }\end{array}$ & 479.0878 & $\mathrm{C}_{21} \mathrm{H}_{20} \mathrm{O}_{13}$ & $\begin{array}{l}316.0226(100) \\
317.0277(24.80)\end{array}$ & $0.95 \pm 0.08^{\mathrm{b}}$ & $1.93 \pm 0.14^{c}$ & $0.86 \pm 0.05^{\mathrm{b}}$ & $0.49 \pm 0.04^{\mathrm{a}}$ \\
\hline 14 & Tetragalonyl glucose & 787.1008 & $\mathrm{C}_{34} \mathrm{H}_{28} \mathrm{O}_{22}$ & $\begin{array}{l}169.0134(5.72) \\
635.0898(35.87)\end{array}$ & - & $2.08 \pm 0.15$ & - & - \\
\hline 15 & $\begin{array}{l}\text { Myricetin-3-O- } \\
\text { rhamnoside }\end{array}$ & 463.0889 & $\mathrm{C}_{21} \mathrm{H}_{20} \mathrm{O}_{12}$ & $\begin{array}{l}316.0227(100) \\
317.0285(30.76)\end{array}$ & $3.11 \pm 0.23^{b}$ & $6.79 \pm 0.25^{c}$ & $1.68 \pm 0.09^{\mathrm{a}}$ & $7.88 \pm 0.32^{\mathrm{d}}$ \\
\hline 16 & Luteolin-7-O-glucoside & 447.0941 & $\mathrm{C}_{21} \mathrm{H}_{20} \mathrm{O}_{11}$ & $\begin{array}{l}285.0407(100) \\
284.0329(24.76)\end{array}$ & $0.82 \pm 0.02^{\mathrm{b}}$ & $1.64 \pm 0.15^{\mathrm{c}}$ & $0.45 \pm 0.03^{\mathrm{a}}$ & $0.41 \pm 0.02^{\mathrm{a}}$ \\
\hline 17 & $\begin{array}{l}\text { Quercetin-3-O- } \\
\text { arabinoside }\end{array}$ & 433.0783 & $\mathrm{C}_{20} \mathrm{H}_{18} \mathrm{O}_{11}$ & $\begin{array}{l}300.0279(100) \\
301.0331(27.06)\end{array}$ & $0.22 \pm 0.01^{\mathrm{a}}$ & $0.46 \pm 0.02^{\mathrm{b}}$ & - & $0.76 \pm 0.04^{b}$ \\
\hline 18 & $\begin{array}{l}\text { Quercetin-3-O- } \\
\text { rhamnoside }\end{array}$ & 447.0934 & $\mathrm{C}_{21} \mathrm{H}_{20} \mathrm{O}_{11}$ & $\begin{array}{l}300.0279(100) \\
301.0351(71.04)\end{array}$ & $3.57 \pm 0.14^{\mathrm{b}}$ & $10.35 \pm 0.36^{c}$ & $2.49 \pm 0.12^{\mathrm{a}}$ & $36.38 \pm 0.59^{\mathrm{d}}$ \\
\hline 19 & Myricetin $O$-gallate & 615.1002 & $\mathrm{C}_{28} \mathrm{H}_{24} \mathrm{O}_{16}$ & $\begin{array}{l}317.0305(100) \\
169.0134(5.61)\end{array}$ & $0.58 \pm 0.02^{\mathrm{a}}$ & $1.41 \pm 0.06^{\mathrm{b}}$ & - & - \\
\hline 20 & $\begin{array}{l}\text { Kaempferol-3-O- } \\
\text { hexoside }\end{array}$ & 431.0986 & $\mathrm{C}_{21} \mathrm{H}_{20} \mathrm{O}_{10}$ & $\begin{array}{l}284.0330(100), \\
285.0406(83.91), \\
255.0300(22.43)\end{array}$ & $0.24 \pm 0.02^{\mathrm{a}}$ & $0.87 \pm 0.05^{\mathrm{b}}$ & - & $6.19 \pm 0.16^{c}$ \\
\hline TPC & mg of gallic acid equivalen & s/g of extra & & & $361.33 \pm 19.90^{c}$ & $434.14 \pm 21.31^{\mathrm{d}}$ & $134.04 \pm 7.21^{\mathrm{a}}$ & $242.75 \pm 15.28^{b}$ \\
\hline TFC & $\mathrm{mg}$ of rutin equivalents/g o & f extracts) & & & $125.07 \pm 10.25^{\mathrm{b}}$ & $162.59 \pm 11.22^{\mathrm{c}}$ & $95.12 \pm 6.27^{\mathrm{a}}$ & $220.97 \pm 15.57^{\mathrm{d}}$ \\
\hline
\end{tabular}

"EE, ethanol extract; TF, free phenolics; TE, esterified phenolics; TI, insoluble-bound phenolics; TPC, total phenolic content; TFC, total flavonoid content. Values were expressed as the mean $\pm \mathrm{SD}(n=3)$. Content of each phenolic compound was expressed as $\mathrm{mg} / \mathrm{g}$ of dry extract. Content values of the same phenolic compound labeled with different superscript letter means significantly different $(p<0.05)$. "Gallic acid standard was used for quantifying the compounds $3,4,5,7,8,9,10,11,14$; protocatechuic acid standard was used for quantifying the compound 6; myricetin-3-O-rhamnoside standard was used for quantifying the compounds 12, 13, 15, 19; luteolin-7-O-glucoside standard was used for quantifying the compound 16; quercetin-3-O-rhamnoside standard was used for quantifying the compounds 17 and 18 ; kaempferol standard was used for quantifying the compound 20.

results of correlation analysis in Table 2 indicated that myricetin3-O-(6"-galloyl) glycoside and myricetin $O$-gallate had the closest relationship with the $\alpha$-glucosidase inhibitory effect. A previous study had reported a similar finding that myricetin 3-O- $\left(2^{\prime \prime \prime}-O-\right.$ galloyl- $\alpha$-L-rhamnopyranoside) and myricetin 3-O-(3"'-O-galloyl$\alpha$-L-rhamnopyranoside) displayed strong inhibitory effects toward $\alpha$-glucosidase with the $\mathrm{IC}_{50}$ values of 3.6 and $7.0 \mu \mathrm{M}$, respectively [26]. Therefore, it may be reasonable to suspect that myricetin-3-O(6"-galloyl) glycoside detected in EE and TF of $R$. chinensis fruits in the present work also possessed a strong inhibitory activity against $\alpha$-glucosidase. Besides, quercetin-3-O-arabinoside, quercetin3-O-rhamnoside and kaempferol-3-O-hexoside also showed a 

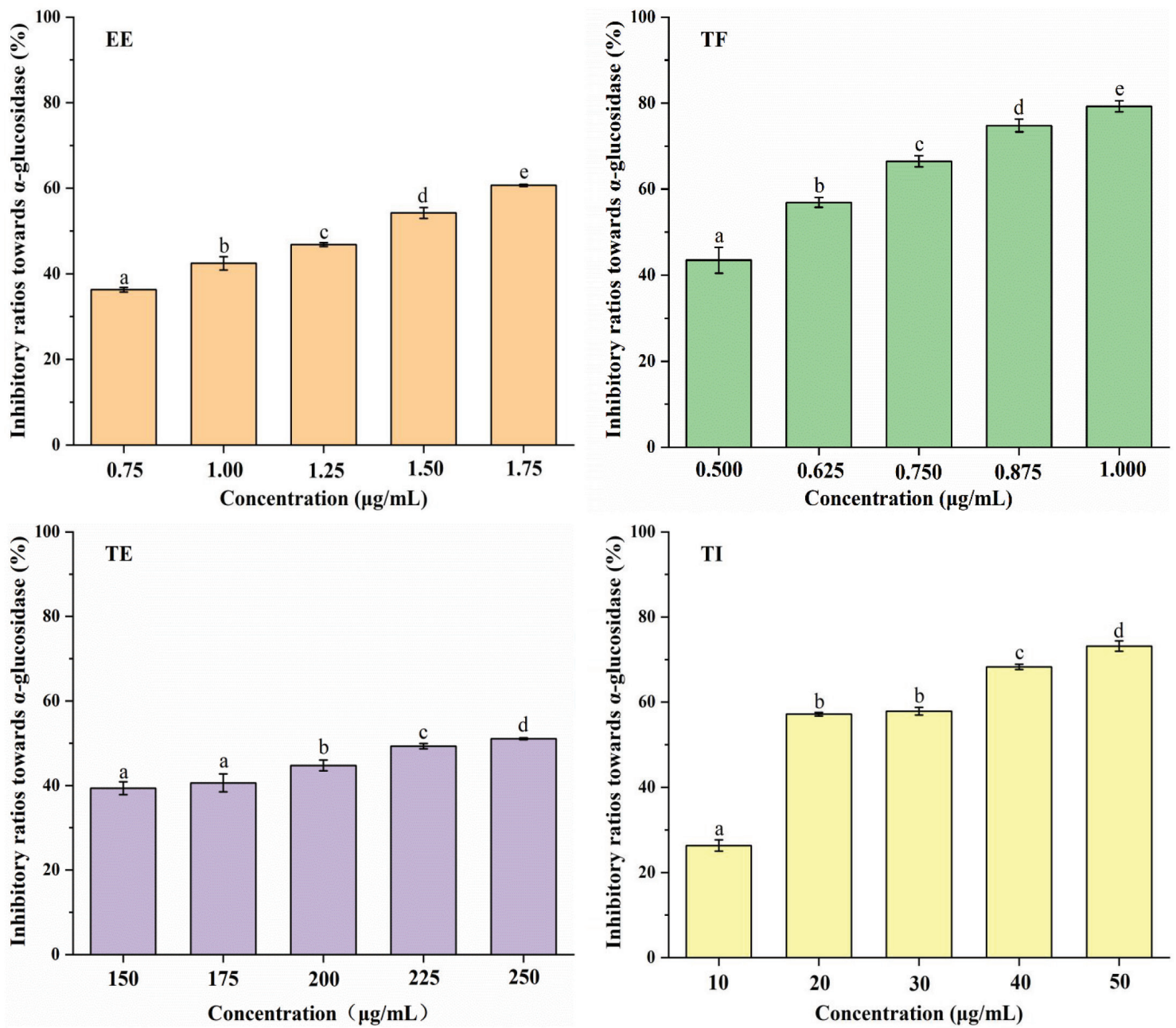

Figure 1 Inhibitory activities of different phenolic-rich extracts from Rhus chinensis Mill. fruits toward $\alpha$-glucosidase. All values are expressed as mean $\pm \mathrm{SD}(n=3)$. Different letters indicate significant differences at the $p<0.05$.

Table 2 Pearson's correlation analyses between various phenolic substances and different biological activities

\begin{tabular}{|c|c|c|c|}
\hline Substances & $\begin{array}{l}\text { The inhibitory effects } \\
\text { against } \alpha \text {-glucosidase }\end{array}$ & $\begin{array}{l}\text { The inhibitory effects } \\
\text { against DPP-IV }\end{array}$ & $\begin{array}{l}\text { The inhibitory effects against } \\
\text { the formation of AGEs }\end{array}$ \\
\hline Gallic acid & $r=-0.128, p>0.05$ & $r=0.152, p>0.05$ & $r=0.141, p>0.05$ \\
\hline Di-O-galloyl-glucoside I & $r=0.188, p>0.05$ & $r=0.528, p<0.05$ & $r=0.400, p<0.05$ \\
\hline Di-O-galloyl-glucoside II & $r=0.272, p<0.05$ & $r=0.541, p<0.05$ & $r=0.445, p<0.05$ \\
\hline Protocatechuic acid & $r=-0.061, p>0.05$ & $r=0.428, p<0.05$ & $r=0.798, p<0.05$ \\
\hline Digallic acid I & $r=0.263, p<0.05$ & $r=0.204, p>0.05$ & $r=0.590, p<0.05$ \\
\hline Trigalloyl glucose I & $r=-0.295, p<0.05$ & $r=-0.092, p>0.05$ & $r=-0.214, p>0.05$ \\
\hline Digallic acid II & $r=0.254, p<0.05$ & $r=0.311, p<0.05$ & $r=0.408, p<0.05$ \\
\hline Trigalloyl glucose II & $r=-0.304, p<0.05$ & $r=0.507, p<0.05$ & $r=0.460, p<0.05$ \\
\hline Methyl gallate & $r=-0.110, p>0.05$ & $r=0.038, p>0.05$ & $r=0.509, p<0.05$ \\
\hline Myricetin-3-O-(6"-galloyl) glycoside & $r=0.453, p<0.05$ & $r=0.516, p<0.05$ & $r=0.421, p<0.05$ \\
\hline Myricetin-3-O-galactoside & $r=-0.285, p<0.05$ & $r=0.084, p>0.05$ & $r=0.594, p<0.05$ \\
\hline Tetragalloyl glucose & $r=-0.292, p<0.05$ & $r=0.443, p<0.05$ & $r=0.444, p<0.05$ \\
\hline Myricetin-3-O-rhamnoside & $r=0.224, p>0.05$ & $r=0.524, p<0.05$ & $r=0.807, p<0.05$ \\
\hline Luteolin-7-O-glucoside & $r=-0.276, p<0.05$ & $r=0.216, p>0.05$ & $r=0.571, p<0.05$ \\
\hline Quercetin-3-O-arabinoside & $r=0.388, p<0.05$ & $r=0.508, p<0.05$ & $r=0.791, p<0.05$ \\
\hline Quercetin-3-O-rhamnoside & $r=0.351, p<0.05$ & $r=0.269, p<0.05$ & $r=0.670, p<0.05$ \\
\hline Myricetin $O$-gallate & $r=0.465, p<0.05$ & $r=0.509, p<0.05$ & $r=0.453, p<0.05$ \\
\hline Kaempferol-3-O-hexoside & $r=0.375, p<0.05$ & $r=0.290, p<0.05$ & $r=0.606, p<0.05$ \\
\hline
\end{tabular}

The value of $r$ was the degree of linear correlation in the Pearson's correlation coefficient analysis. The absolute value of $r$ reveals the correlation relationship between the various phenolics and different bioactivities. The higher value shows the stronger relationship, and a positive value indicates a positive correlation, and a negative value indicates a negative correlation. 
significantly positive correlation to the $\alpha$-glucosidase inhibitory effect (Table 2). However, luteolin-7-O-glucoside, which had been reported to possess a strong inhibitory activity on $\alpha$-glucosidase [27], displayed a significantly negative correlation to the $\alpha$-glucosidase inhibitory activity in the present work (Table 2). This paradoxical phenomenon may be due to the interactions between different phenolic substances in the extract. Acarbose, as the positive control, has the lowest $\mathrm{IC}_{50}$ value for $0.16 \pm 0.02 \mu \mathrm{g} / \mathrm{mL}$ under the current experimental condition.

The inhibitory activities to DPP-IV of all tested samples are illustrated in Figure 2. Those four extracts could also strongly inhibit DPP-IV in a dose-response manner and these four fractions exhibited different inhibitory activities. Among them, TF possessed the strongest inhibitory activity with the lowest IC $_{50}$ value of $66.08 \pm 1.36 \mu \mathrm{g} / \mathrm{mL}(p<0.05)$. The inhibitory ratios of TF varied from $40.94 \%$ to $65.23 \%$ when the tested concentrations ranged from 50 to $90 \mu \mathrm{g} / \mathrm{mL}$. The IC I0 $_{0}$ values of EE and TI were $125.83 \pm 3.34$ and $164.19 \pm 3.37 \mu \mathrm{g} / \mathrm{mL}$, respectively. TE, however, had the highest $794.94 \pm 13.25 \mu \mathrm{g} / \mathrm{mL}$, indicating that the TE exerted the weakest DPP-IV inhibitory effect $(p<0.05)$. According to the results summarized in Table 2, it is found that di-O-galloyl-glucoside I and its isomer may be the phenolic substances that contributed significantly on DPP-IV inhibition. Besides, myricetin-3-O-rhamnoside, myricetin-3-O-(6"-galloyl) glycoside, quercetin-3-O-arabinoside and myricetin $O$-gallate also showed significantly positive correlation to the DPP-IV inhibition. It is worth noting that trigalloyl glucose I had no remarkable correlation to the inhibitory effect, but its isomer did. This result may be due to their different structure. Previous study had found that gallic acid possessed a good inhibition toward DPP-IV, but protocatechuic acid did not show a strong DPP-IV inhibition [6]. However, according to Table 2 in this study, protocatechuic acid instead of gallic acid displayed a significant correlation to DPP-IV inhibition. This different result may be due to complicated composition of extracts used in the present work and the interaction between different substances. In a previous study, a similar phenomenon was also found: cyanidin3-O-glucoside had obviously lower value of $r$ than rutin when analyzed with the DPP-IV inhibition results of different exerts from Prinsepia utilis Royle fruits, while the experimental results of pure compounds showed that cyanidin-3-O-glucoside possessed a much better DPP-IV inhibition than rutin [28]. Another study had also confirmed that the inhibition effect on DPP-IV of fermented blueberry and blackberry not due to the existence of a certain compound but the several phenolic compounds [29].

\subsection{Analyses of Synergistic Effects}

Since myricetin-3-O-rhamnoside and quercetin-3-O-rhamnoside were the main flavonoids detected in all extracts of $R$. chinensis fruits, the $\alpha$-glucosidase and DPP-IV inhibitory effects of myricetin3-O-rhamnoside and quercetin-3-O-rhamnoside and their combinations were measured. The inhibition results of these two compounds at different concentrations against $\alpha$-glucosidase and DPP-IV are displayed in Figure 3. Both myricetin-3-O-rhamnoside
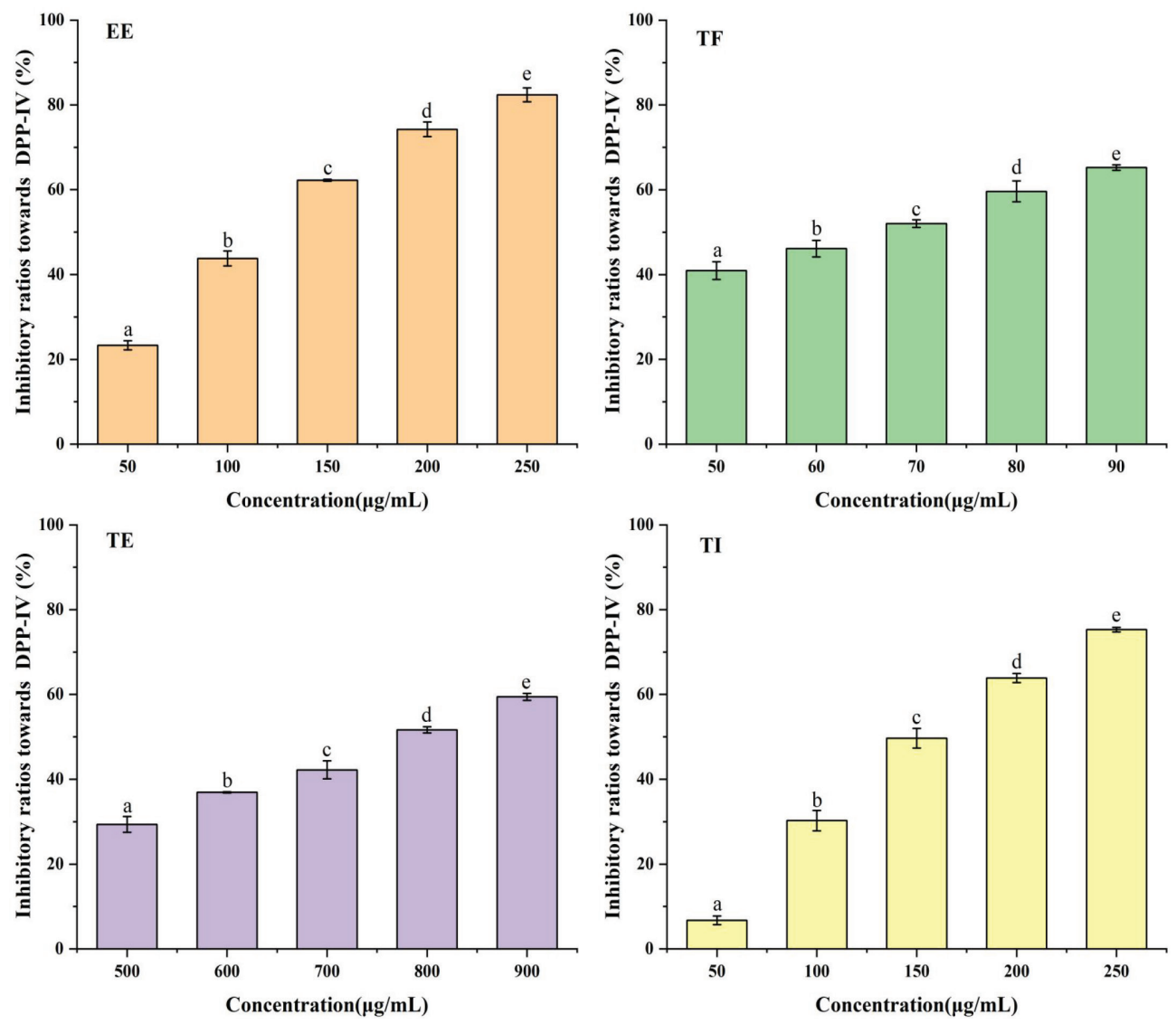

Figure 2 Inhibitory activities of different phenolic-rich extracts from Rhus chinensis Mill. fruits toward DPP-IV. All values are expressed as mean \pm SD $(n=3)$. Different letters indicate significant differences at the $p<0.05$. 


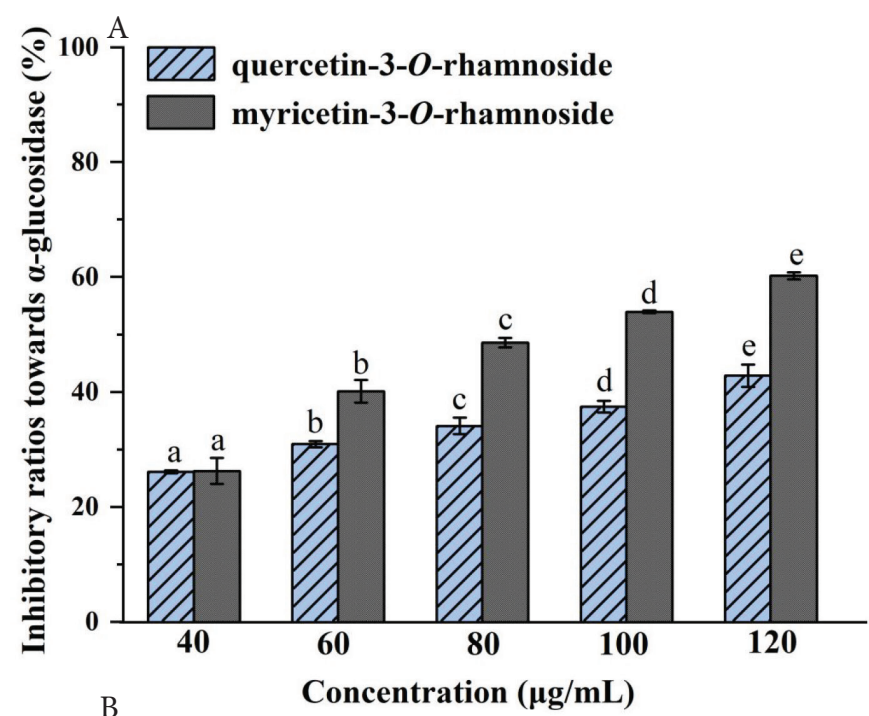

and quercetin-3-O-rhamnoside showed good inhibitory effects toward $\alpha$-glucosidase and DPP-IV in a dose-dependent manner, and myricetin-3-O-rhamnoside exhibited better inhibitory capacities toward $\alpha$-glucosidase and DPP-IV than quercetin-3-O-rhamnoside. The $\mathrm{IC}_{50}$ values of myricetin-3-O-rhamnoside and quercetin3-O-rhamnoside of $\alpha$-glucosidase inhibition were $93.12 \pm 0.32$ and $146.30 \pm 8.78 \mu \mathrm{g} / \mathrm{mL}$, and their $\mathrm{IC}_{50}$ values of DPP-IV inhibition were $67.83 \pm 2.97$ and $71.79 \pm 1.05 \mu \mathrm{g} / \mathrm{mL}$, respectively.

Table 3 presents the interaction results of myricetin-3-O-rhamnoside and quercetin-3-O-rhamnoside on $\alpha$-glucosidase inhibition. As shown in Table 3, when the ratio of myricetin-3-O-rhamnoside and quercetin-3-O-rhamnoside was set as $1: 1$, the $\mathrm{CI}$ value dropped from 0.958 to 0.826 when the concentration ranging from 40 to $120 \mu \mathrm{g} / \mathrm{mL}$, suggesting that the interaction effects on $\alpha$-glucosidase inhibition of those two compounds changed from additive effect to synergistic effect. When the ratio of myricetin-3-O-rhamnoside and quercetin-3-O-rhamnoside was set as $1: 2$, the $\mathrm{CI}$ value dropped from 1.278 to 0.988 when the myricetin-3-O-rhamnoside concentration ranging from 20 to $60 \mu \mathrm{g} / \mathrm{mL}$, indicating that the interaction effects on $\alpha$-glucosidase inhibition of those two compounds changed from antagonistic effect to additive effect. This finding was similar with the previous study that the interaction effects of catechin-caffeic acid combination on $\alpha$-glucosidase inhibition changed from antagonistic to addictive effect at ratio of $1: 2$ [30]. According to the interaction results, the different inhibitory abilities of the different extracts toward $\alpha$-glucosidase may be due to different interaction effects of phenolic compounds in the extracts.

Table 4 presents the interactions between myricetin-3-O-rhamnoside and quercetin-3-O-rhamnoside on DPP-IV inhibition. When the concentration ratio of myricetin-3-O-rhamnoside and quercetin3-O-rhamnoside was set as 1:1, unlike the trend of the $\alpha$-glucosidase inhibition, CI values gradually increased with the increasing concentration. During the test concentrations from 40 to $120 \mu \mathrm{g} / \mathrm{mL}$, CI increased from 1.493 to 1.867 , all values were more than 1.10 , suggesting that those two compounds were always antagonistic effect when inhibiting DPP-IV in combination. When the concentration ratio of myricetin-3-O-rhamnoside and quercetin3-O-rhamnoside was set as 1:2, a similar phenomenon was observed,

Figure 3 Inhibitory activities of myricetin-3-O-rhamnoside and quercetin-3-O-rhamnoside toward $\alpha$-glucosidase (A) and DPP-IV (B). All the values are expressed as mean $\pm \mathrm{SD}(n=3)$. Different letters indicate significant differences at the $p<0.05$.

Table 3 Interaction between myricetin-3-O-rhamnoside and quercetin-3-O-rhamnoside on $\alpha$-glucosidase inhibition

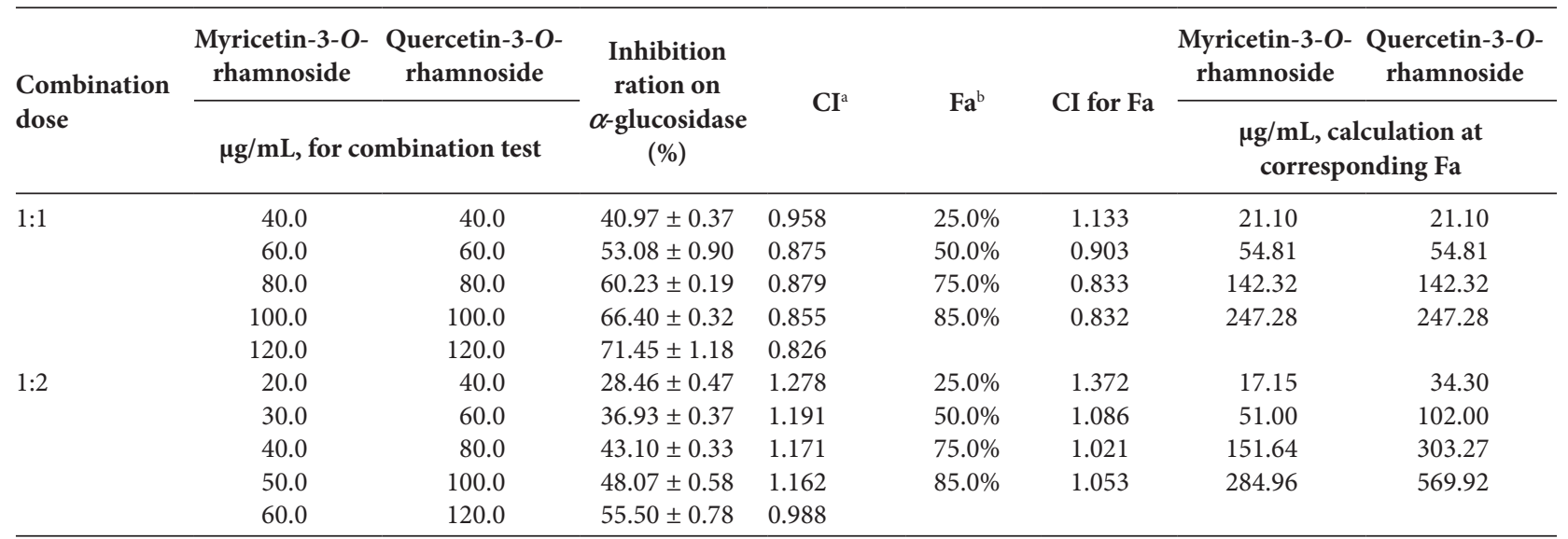

${ }^{\mathrm{a}} \mathrm{CI}$, combination index. $\mathrm{CI} \leq 0.90,0.90<\mathrm{CI}<1.10$ and $\mathrm{CI} \geq 1.10$ indicate synergistic, additive and antagonistic effects, respectively. ${ }^{\mathrm{b}} \mathrm{Fa}$, fraction affected by the combination dose of myricetin-3-O-rhamnoside and quercetin-3-O-rhamnoside. 
Table 4 Interaction between myricetin-3-O-rhamnoside and quercetin-3-O-rhamnoside on DPP-IV inhibition

\begin{tabular}{|c|c|c|c|c|c|c|c|c|}
\hline \multirow{2}{*}{$\begin{array}{l}\text { Combination } \\
\text { dose }\end{array}$} & $\begin{array}{l}\text { Myricetin-3-O- } \\
\text { rhamnoside }\end{array}$ & $\begin{array}{l}\text { Quercetin-3-O- } \\
\text { rhamnoside }\end{array}$ & \multirow{2}{*}{$\begin{array}{l}\text { Inhibition ration } \\
\text { on DPP-IV (\%) }\end{array}$} & \multirow{2}{*}{$\mathbf{C I}^{\mathrm{a}}$} & \multirow{2}{*}{$\mathbf{F a}^{\mathrm{b}}$} & \multirow{2}{*}{$\mathrm{CI}$ for $\mathrm{Fa}$} & $\begin{array}{l}\text { Myricetin-3-O- } \\
\text { rhamnoside }\end{array}$ & $\begin{array}{c}\text { Quercetin-3-O } \\
\text { rhamnoside }\end{array}$ \\
\hline & \multicolumn{2}{|c|}{$\mu \mathrm{g} / \mathrm{mL}$, for combination test } & & & & & \multicolumn{2}{|c|}{$\begin{array}{l}\mu \mathrm{g} / \mathrm{mL}, \text { calculation at } \\
\text { corresponding } \mathrm{Fa}\end{array}$} \\
\hline \multirow[t]{5}{*}{$1: 1$} & 40.0 & 40.0 & $19.42 \pm 1.84$ & 1.493 & $25.0 \%$ & 1.590 & 25.21 & 25.21 \\
\hline & 60.0 & 60.0 & $39.43 \pm 0.91$ & 1.782 & $50.0 \%$ & 1.736 & 54.81 & 54.81 \\
\hline & 80.0 & 80.0 & $58.17 \pm 1.77$ & 1.802 & $75.0 \%$ & 1.897 & 142.32 & 142.32 \\
\hline & 100.0 & 100.0 & $69.85 \pm 1.94$ & 1.844 & $85.0 \%$ & 1.998 & 137.69 & 137.69 \\
\hline & 120.0 & 120.0 & $77.68 \pm 1.18$ & 1.867 & & & & \\
\hline \multirow[t]{5}{*}{$1: 2$} & 20.0 & 40.0 & $12.37 \pm 0.5$ & 1.351 & $25.0 \%$ & 1.597 & 17.02 & 34.30 \\
\hline & 30.0 & 60.0 & $28.93 \pm 0.89$ & 1.701 & $50.0 \%$ & 2.055 & 39.17 & 78.34 \\
\hline & 40.0 & 80.0 & $41.59 \pm 1.34$ & 1.884 & $75.0 \%$ & 2.648 & 90.15 & 180.30 \\
\hline & 50.0 & 100.0 & $50.65 \pm 1.26$ & 2.070 & $85.0 \%$ & 3.067 & 146.06 & 292.12 \\
\hline & 60.0 & 120.0 & $58.10 \pm 1.92$ & 2.207 & & & & \\
\hline
\end{tabular}

${ }^{a} \mathrm{CI}$, combination index. $\mathrm{CI} \leq 0.90,0.90<\mathrm{CI}<1.10$ and $\mathrm{CI} \geq 1.10$ indicate synergistic, additive and antagonistic effects, respectively. ${ }^{\mathrm{b}} \mathrm{Fa}$, fraction affected by the combination dose of myricetin-3-O-rhamnoside and quercetin-3-O-rhamnoside.

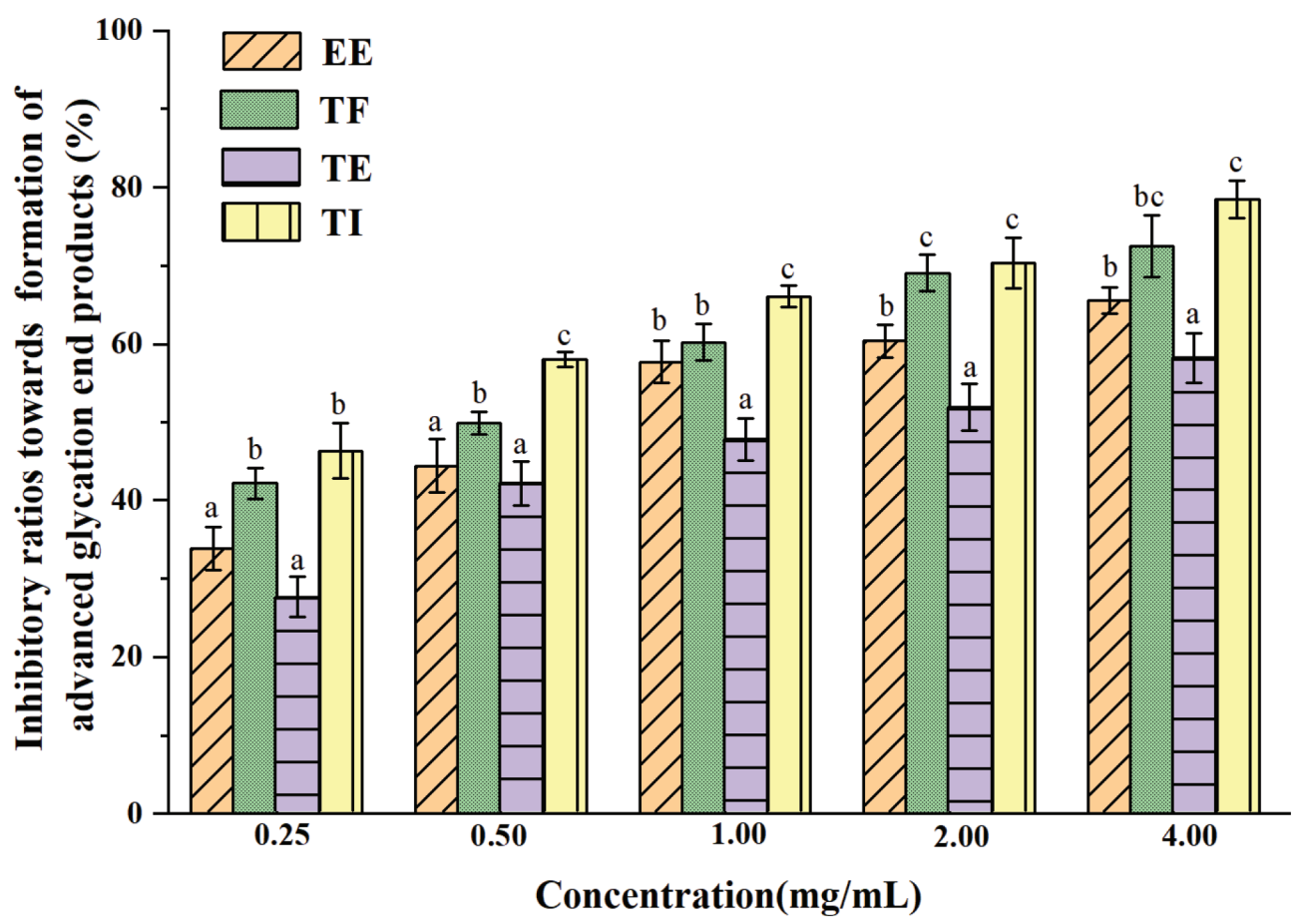

Figure 4 Inhibitory activities of different phenolic-rich extracts from Rhus chinensis Mill. fruits toward the advanced glycation end products formation. All values are expressed as mean $\pm \operatorname{SD}(n=3)$. Different letters indicate significant differences at the $p<0.05$.

namely CI value gradually increased with the increasing concentration and interaction type was always antagonistic effect. This finding of the antagonistic effect may be used to explain why the extracts from $R$. chinensis fruits showing weaker inhibitory effects than myricetin-3-O-rhamnoside or quercetin-3-O-rhamnoside. However, even under antagonistic action, the inhibitory effects of those extracts were also pretty good, especially EE and TF, which further confirmed the prospect of $R$. chinensis fruits on the prevention or treatment T2DM.

\subsection{Inhibition to the Formation of AGEs}

Advanced glycation ends are a kind of irreversible final products of Maillard reaction, which are formed by a series of reactions between the free amino groups of protein, amino acid, lipid or nucleic acid and carbonyl group of reducing sugar, like condensation, rearrangement, cleavage and oxidation modification [31,32]. Additional, AGEs are closely associated to the diabetic that glycosylation facilitates the development of diabetic complications [33]. Inhibiting the generation of AGEs is considered as an effective method to prevent or delay the incidence of many chronic diseases caused by diabetes.

As can be seen from Figure 4, the four extracts presented different inhibitory capacities towards the AGEs formation under the tested concentrations in a dose-dependent manner. Among those extracts, the TI possessed the strongest inhibitory capacity, while TE showed the weakest suppression $(p<0.05)$. At the low concentrations $(0.25$ and $0.50 \mathrm{mg} / \mathrm{mL})$, there was no significant difference between EE 
and TE. However, when the concentration of EE increased to 1.00 $\mathrm{mg} / \mathrm{mL}$, its inhibitory activity has no significant difference with that of TF $(p>0.05)$ but showed significantly different from that of TE and TI $(p<0.05)$. When the concentration reached $4.00 \mathrm{mg} / \mathrm{mL}$, the inhibitory capacities of TF and TI exceeded $70 \%$. The $\mathrm{IC}_{50}$ values of the EE, TF, TE and TI were $0.87 \pm 0.06,0.50 \pm 0.04,1.94 \pm 0.15$ and $0.43 \pm 0.03 \mathrm{mg} / \mathrm{mL}$, respectively.

It is well known that the free radicals are involved in the formation of AGEs, and previous studies had proved that the anti-glycation of phenolic compounds may be due to their good antioxidant properties $[33,34]$. Our previous study had reported that different extracts of $R$. chinensis fruits exhibited strong ABTS and DPPH radical scavenging activities [10]. Moreover, the ethanol extract of $R$. chinensis fruits can improve the antioxidant defensive systems in rats with nonalcoholic fatty liver and mice with fibrosis liver in vivo [11,12]. According to those results, it is reasonable to assume that the good inhibitory effect of those extracts toward AGEs formation may be due to their good antioxidant activities. Moreover, as shown in Table 2, both protocatechuic acid and myricetin-3-O-rhamnoside possessed the highest $r$-values, revealing that these two substances may contribute significantly in the inhibitory effect against the AGEs formation. Previous studies had reported that these two compounds also exhibited strong antioxidant or radical scavenging activities $[35,36]$. Besides, quercetin-3-O-arabinoside, quercetin-3-O-rhamnoside as well as kaempferol-3-O-hexoside also contributed significantly to the suppression of AGEs formation, which may be also due to their good antioxidant properties [37,38].

\section{CONCLUSION}

In this study, the in vitro anti-diabetic effects of different phenolicrich extracts of $R$. chinensis fruits, namely TF, TE, TI and EE, were investigated based on their inhibitory activities toward $\alpha$-glucosidase, DPP-IV and the AGEs formation. Results showed that the TF exhibited the strongest inhibitory effects against $\alpha$-glucosidase and DPP-IV, and TI possessed the strongest inhibitory activity on the AGEs formation. Myricetin-3-O-rhamnoside and quercetin-3-O-rhamnoside, two main flavonoids detected in all extracts, also showed pretty good inhibitory effects towards $\alpha$-glucosidase and DPP-IV. Interaction analysis revealed that those two compounds displayed additive or synergistic effects on $\alpha$-glucosidase inhibition, however, showed antagonistic effect on DPP-IV inhibition. Correlation results indicated that myricetin3-O-(6"-galloyl) glycoside and myricetin $O$-gallate contributed remarkably to the $\alpha$-glucosidase inhibition of those extracts, while di-O-galloyl-glucoside and its isomer may significantly contributed to the DPP-IV inhibition. In addition, protocatechuic acid and myricetin-3-O-rhamnoside may take a main responsibility to suppress the AGEs formation. This study suggested that $R$. chinensis fruits may have potential development and utilization prospects in prevent or treat type 2 diabetes.

\section{CONFLICTS OF INTEREST}

The authors declare they have no conflicts of interest.

\section{AUTHORS' CONTRIBUTION}

XL contributed in conceptualization, experiment design, data curation and original draft writing. YF and QM contributed in methodology and in validation. SC and JY contributed in writing review and editing. SC contributed in supervision and project administration.

\section{ACKNOWLEDGMENTS}

The present work was financially supported by Kunming Science and Technology Innovation Center Demonstration Construction Project (Grant No. 2019-1-N-25318000003141), Scientific Research Foundation of Education Department of Yunnan Province (Grant No. 2019J0047) and Applied Basic Research Project of Yunnan Province (Grant No. 2019FD051).

\section{SUPPLEMENTARY MATERIAL}

Supplementary data related to this article can be found at https:// doi.org/10.2991/efood.k.210222.002.

\section{REFERENCES}

[1] Zhao R, Khafipour E, Sepehri S, Huang F, Beta T, Shen GX. Impact of Saskatoon berry powder on insulin resistance and relationship with intestinal microbiota in high fat-high sucrose diet-induced obese mice. J Nutr Biochem 2019;69:130-8.

[2] Shi R, Chen Y, Liao Y, Li R, Lin C, Xiu L, et al. Research status of differentially expressed noncoding RNAs in type 2 diabetes patients. Biomed Res Int 2020;2020:3816056.

[3] Pittas AG, Lau J, Hu FB, Dawson-Hughes B. The role of vitamin D and calcium in type 2 diabetes. A systematic review and meta-analysis. J Clin Endocrinol Metab 2007;92:2017-29.

[4] Dall TM, Zhang Y, Chen YJ, Quick WW, Yang, WG, Fogli J. The economic burden of diabetes. Health aff (Millwood) 2010;29: 297-303.

[5] González-Abuín N, Martínez-Micaelo N, Blay M, Pujadas G, Garcia-Vallvé S, Pinent M, et al. Grape seed-derived procyanidins decrease dipeptidyl-peptidase 4 activity and expression. J Agric Food Chem 2012;60:9055-61.

[6] Gao Y, Zhang Y, Zhu J, Li B, Li Z, Zhu W, et al. Recent progress in natural products as DPP-4 inhibitors. Future Med Chem 2015;7:1079-89.

[7] Kim JM, Lee YM, Lee GY, Jang DS, Bae KH, Kim JS. Constituents of the roots of Pueraria lobata inhibit formation of advanced glycation end products (AGEs). Arch Pharm Res 2006;29:821-5.

[8] Jang DS, Lee GY, Lee YM, Kim YS, Sun H, Kim DH, et al. Flavan3-ols having a $\gamma$-lactam from the roots of Actinidia arguta inhibit the formation of advanced glycation end products in vitro. Chem Pharm Bull (Tokyo) 2009;57:397-400.

[9] Djakpo O, Yao W. Rhus chinensis and Galla Chinensis - folklore to modern evidence: review. Phytother Res 2010;24:1739-47.

[10] Zhang C, Ma Y, Zhao Y, Hong Y, Cai S, Pang M. Phenolic composition, antioxidant and pancreatic lipase inhibitory activities of Chinese sumac (Rhus chinensis Mill.) fruits extracted by different 
solvents and interaction between myricetin-3-O-rhamnoside and quercetin-3-O-rhamnoside. Int J Food Sci Technol 2018;53: 1045-53.

[11] Zhou J, Liu X, Chen T, Cheng G, Cai S. Preventive effect of ethanol extract from Chinese sumac fruits against tetrachloromethaneinduced liver fibrosis in mice. Food Funct 2020;11:7061-72.

[12] Wu Z, Zhang Y, Gong X, Cheng G, Pu S, Cai S. The preventive effect of phenolic-rich extracts from Chinese sumac fruits against nonalcoholic fatty liver disease in rats induced by a high-fat diet. Food Funct 2020;11:799-812.

[13] Wu Z, Ma Y, Gong X, Zhang Y, Zhao L, Cheng G, et al. Rhus chinensis Mill. fruits prevent high-fat/ethanol diet-induced alcoholic fatty liver in rats via AMPK/SREBP-1/FAS signaling pathway. J Funct Food 2019;61:103498.

[14] Zhang C, Ma Y, Gao F, Zhao Y, Cai S, Pang M. The free, esterified, and insoluble-bound phenolic profiles of Rhus chinensis Mill. fruits and their pancreatic lipase inhibitory activities with molecular docking analysis. J Funct Food 2018;40:729-35.

[15] Zhou J, Ma Y, Jia Y, Pang M, Cheng G, Cai S. Phenolic profiles, antioxidant activities and cytoprotective effects of different phenolic fractions from oil palm (Elaeis guineensis Jacq.) fruits treated by ultra-high pressure. Food Chem 2019;288:68-77.

[16] Huang S, Ma Y, Sun D, Fan J, Cai S. In vitro DNA damage protection and anti-inflammatory effects of Tartary buckwheats (Fagopyrum tataricum L. Gaertn) fermented by filamentous fungi. Int J Food Sci Technol 2017;52:2006-17.

[17] Wu X, Ding H, Hu X, Pan J, Liao Y, Gong D, et al. Exploring inhibitory mechanism of gallocatechin gallate on $\alpha$-amylase and $\alpha$-glucosidase relevant to postprandial hyperglycemia. J Funct Food 2018;48:200-9.

[18] Liu W, Ma H, Frost L, Yuan T, Dain JA, Seeram NP. Pomegranate phenolics inhibit formation of advanced glycation endproducts by scavenging reactive carbonyl species. Food Funct 2014;5: 2996-3004.

[19] Yu M, Yang L, Xue Q, Yin P, Sun L, Liu Y. Comparison of free, esterified, and insoluble-bound phenolics and their bioactivities in three organs of Lonicera japonica and L. macranthoides. Molecules 2019;24:970.

[20] Rahman MJ, de Camargo AC, Shahidi F. Phenolic profiles and antioxidant activity of defatted camelina and sophia seeds. Food Chem 2018;240:917-25.

[21] Yang L, Yin P, Li K, Fan H, Xue Q, Li X, et al. Seasonal dynamics of constitutive levels of phenolic components lead to alterations of antioxidant capacities in Acer truncatum leaves. Arab J Chem 2018;11:14-25.

[22] Park SY, Kim JK, Lee SY, Oh SD, Lee SM, Jang JS, et al. Comparative analysis of phenolic acid profiles of rice grown under different regions using multivariate analysis. Plant Omics 2014;7:430-7.

[23] Giancarlo S, Rosa LM, Nadjafi F, Francesco M. Hypoglycaemic activity of two spices extracts: Rhus coriaria L. and Bunium persicum Boiss. Nat Prod Res 2006;20:882-6.

[24] Zhang B, Deng Z, Ramdath DD, Tang Y, Chen PX, Liu R, et al. Phenolic profiles of 20 Canadian lentil cultivars and their contribution to antioxidant activity and inhibitory effects on $\alpha$-glucosidase and pancreatic lipase. Food Chem 2015;172:862-72.
[25] Choudhary DK, Chaturvedi N, Singh A, Mishra A. Characterization, inhibitory activity and mechanism of polyphenols from faba bean (gallic-acid and catechin) on $\alpha$-glucosidase: insights from molecular docking and simulation study. Prep Biochem Biotechnol 2020;50:123-32.

[26] Phuong NH, Thuy NTL, Duc NT, Tuyet NTA, Mai NTT, Phung NKP. A new glycoside and in vitro evalution of $\alpha$-glucosidase inhibitory activity of constituents of the mangrove Lumnitzera racemosa. Nat Prod Commun 2017;12:1751-4.

[27] Pereira DF, Cazarolli LH, Lavado C, Mengatto V, Figueiredo MSRB, Guedes A, et al. Effects of flavonoids on $\alpha$-glucosidase activity: potential targets for glucose homeostasis. Nutrition 2011; 27:1161-7.

[28] Liu X, Shi J, Yi J, Zhang X, Ma Q, Cai S. The effect of in vitro simulated gastrointestinal digestion on phenolic bioaccessibility and bioactivities of Prinsepia utilis Royle fruits. LWT 2021;138:110782.

[29] Fan J, Johnson MH, Lila MA, Yousef G, de Mejia EG. Berry and citrus phenolic compounds inhibit dipeptidyl peptidase IV: implications in diabetes management. Evid Based Complement Alternat Med 2013;2013:479505.

[30] Zhou Q, Zhou J, Liu X, Zhang YB, Cai S. Digestive enzyme inhibition of different phenolic fractions and main phenolic compounds of ultra-high-pressure-treated palm fruits: interaction and molecular docking analyses. J Food Qual 2020;2020:8811597.

[31] Singh R, Barden A, Mori T, Beilin L. Advanced glycation endproducts: a review. Diabetologia 2001;44:129-46.

[32] Sugiyama S, Miyata T, Horie K, Lida Y, Tsuyuki M, Tananka H, et al. Advanced glycation end-products in diabetic nephropathy. Nephrol Dial Transplant 1996;11:91-4.

[33] Wu CH, Huang SM, Lin JA, Yen GC. Inhibition of advanced glycation endproduct formation by foodstuffs. Food Funct 2011;2:224-34.

[34] Abdallah HM, El-Bassossy H, Mohamed GA, El-Halawany AM, Alshali KZ, Banjar ZM. Phenolics from Garcinia mangostana inhibit advanced glycation endproducts formation: effect on amadori products, cross-linked structures and protein thiols. Molecules 2016;21:251.

[35] Elansary HO, Szopa A, Klimek-Szczykutowicz M, Jafernik K, Ekiert H, Mahmoud EA, et al. Mammillaria species_polyphenols studies and anti-cancer, anti-oxidant, and anti-bacterial activities. Molecules 2020;25:131.

[36] Hayder N, Bouhlel I, Skandrani I, Kadri M, Steiman R, Guiraud $\mathrm{P}$, et al. In vitro antioxidant and antigenotoxic potentials of myricetin-3-O-galactoside and myricetin-3-O-rhamnoside from Myrtus communis: modulation of expression of genes involved in cell defence system using cDNA microarray. Toxicol In Vitro 2008;22:567-81.

[37] Ghanta S, Banerjee A, Poddar A, Chattopadhyay S. Oxidative DNA damage preventive activity and antioxidant potential of Stevia rebaudiana (Bertoni) Bertoni, a natural sweetener. J Agric Food Chem 2007;55:10962-7.

[38] Liu Y, Chen P, Zhou M, Wang T, Fang S, Shang X, et al. Geographic variation in the chemical composition and antioxidant properties of phenolic compounds from Cyclocarya paliurus (Batal) Iljinskaja leaves. Molecules 2018;23:2440. 